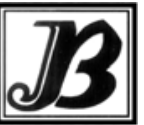

J. bio-sci. 17: 71-76, 2009

ISSN 1023-8654

http://www.banglajol.info/index.php/JBS/index

\title{
ISOLATION AND CHARACTERIZATION OF CHROMATE RESISTANT AND REDUCING BACTERIA FROM TANNERY EFFLUENT OF CHITTAGONG, BANGLADESH
}

\author{
M Fakruddin ${ }^{*}$, Reaz Mohammad Mazumdar, Towhida Khanom Tania ${ }^{1}$, Saiful Islam, Meher Nigad Nipa, \\ Asif Iqbal' ${ }^{1}$, Habibur R Bhuiyan \\ *Industrial Microbiology Research Division, BCSIR Laboratories, Chittagong, Bangladesh \\ ${ }^{1}$ Department of Genetic Engineering and Biotechnology, Shahjalal University of Science \& Technology, \\ Sylhet, Bangladesh
}

\begin{abstract}
Context: Waste water containing Chromium $\left(\mathrm{Cr}^{6+}\right)$ is by far the most important environmental challenge being faced.

Objectives: The present study was planned on the isolation and characterization of chromate resistant and reducing bacterial strains in order to use them for detoxification of chromate.

Materials and Methods: Water samples were collected to isolate microorganisms from tannery effluent of Baluchara, Chittagong and inoculated into Luria-Bertani medium with added $\mathrm{Cr}^{6+}$ as $\mathrm{K}_{2} \mathrm{Cr}_{2} \mathrm{O}_{7}$. The organisms have been identified and studied for $\mathrm{Cr}^{6+}$ reduction-ability in growth dependent manner.

Results: A total of 35 isolates have been selected as potential organism belonging to the species of Moraxella (14.3\%), Bacillus (11.43\%), Streptococcus (25.72\%), Staphylococcus (5.7\%), Salmonella $(12.3 \%)$, E. coli $(13.3 \%)$, Enterobacter $(11.3 \%)$, Hafnia alvei $(2.45 \%)$ and Alcaligenes $(3.5 \%)$. The selected isolates were able to tolerate at least $500 \mathrm{mg} / \mathrm{l} \mathrm{of} \mathrm{Cr}^{6+}$. The total $\mathrm{Cr}^{6+}$ concentration of the effluent sample analysed was found to be about $23.73 \mathrm{mg} / \mathrm{l}$ as determined by Atomic Absorption Spectrophotometry. Two of the isolates reduced $38 \%$ and $32 \%$ of $\mathrm{Cr}^{6+}$ added to the medium. Another 7 isolates showed $\mathrm{Cr}^{6+}$ reducing capability ranging from 18 to $22 \%$.
\end{abstract}

Conclusion: As the isolates have turned out to successfully reduce $\mathrm{Cr}^{6+}$ in this study, these can be used for the development of bioremediation process.

Key words: Enzymatic reduction, Bioremediation, Chromium, Ecotoxicity, Tannery.

\section{Introduction}

In the wake of industrialization, consequent urbanization and ever increasing population, the basic amenities of life viz. air, water and land are being polluted continuously (Chhikara et al. 2008). The bio-magnification of heavy metals in ecosystem is a major threat to human life (Yigit and Altindag 2006, Hooda 2007). Chromium $\mathrm{VI}\left(\mathrm{Cr}^{6+}\right)$ is one of the highly toxic heavy metals. It enters into the natural water bodies through the industrial effluents creating water pollution (Singh 1994). Chromium and its compounds are widely used in electroplating, leather tanning, cement, dyeing, metal processing, wood preservatives, paint and pigments, textile, steel fabrication and canning industries. These industries produce large quantities of toxic wastewater effluents (Raji and Anirudhan 1997). The industrial effluents containing chromium compounds in hexavalent form are released directly or indirectly into natural water sources, mostly without proper effluent treatment (Shakoori et al. 2000). Two stable oxidation states of Chromium persist in the environment, $\mathrm{Cr}^{3+}$ and $\mathrm{Cr}^{6+}$ (Raji and Anirudhan 1997).

" Corresponding author 
Leather tanning is one of the main sectors in Bangladesh's leather industry. Large amounts of chrome powder and chrome liquor are used during tanning process. More than 1,70,000 tons of chromium wastes are discharged to the environment annually as a consequence of industrial manufacturing activities (Kamaludeen et al. 2003). Due to its high oxidation potential, it can easily penetrate biological membranes and cause health hazards (Chaudhary et al. 2003). Feeds and fertilizer production from tanned skin-cut wastes (SCW) is the most direct phenomenon of chromium ecotoxicity leading to food chain contamination in Bangladesh (Rafiqullah et al. 2008). The SCW is protein-rich and indiscriminately used to produce poultry and fish feeds, and organic fertilizer. It is reported that feed ingredients produced from SCW contained chromium at levels as high as $2.49 \%$ (Hossain et al. 2007).

Reduction of $\mathrm{Cr}^{6+}$ is one of the important mechanisms for its detoxification from waste water. Hexavalent $\mathrm{Cr}$ is known to be 100-1000 times more toxic than the trivalent form (Gauglhofer and Bianchi 1991). Bacterial biomass can be used as an economical option for removing chromium from the effluent by reduction and bioaccumulation. The organics present in effluents are utilized as nutrients for the microorganisms which in turn reduce $\mathrm{Cr}^{6+}$ to $\mathrm{Cr}^{3+}$ leading to the removal of $\mathrm{Cr}^{6+}$ from the environment (Singh 1994). Microorganisms are advantageous for metal detoxification as they are easy to grow, resulting in a rapid production of biomass, and are part of natural environment (Faryal et al. 2007). It is therefore advantageous to develop a bioprocess utilizing selected indigenous microbes that are both $\mathrm{Cr}^{6+}$ - resistant and $\mathrm{Cr}^{6+}-$ reducing. Therefore, the present study was planned on the isolation and characterization of chromate resistant and reducing bacterial strains and to compare their growth behavior in different levels of $\mathrm{Cr}$ concentration in order to use them for detoxification of chromate in an integrated bioremediation system.

\section{Materials and Methods}

Study area and sample collection: Samples of tannery effluent releasing from two tanneries situated at Baluchara, Chittagong were collected once a month between March to May 2010. During sampling precautions were taken to minimize cross-contamination of samples. Samples were aseptically collected in sterile bottles and transported to the laboratory of Industrial Microbiology Research Division, BCSIR Laboratories, Chittagong in an insulated box with ice to maintain a temperature ranging from $4{ }^{\circ} \mathrm{C}$ to $6{ }^{\circ} \mathrm{C}$ (APHA 1998). Samples were stored in ice for up to $6 \mathrm{~h}$ from the time of collection for transport and subsequent analysis in the laboratory.

Enrichment culture of $\mathrm{Cr}(\mathrm{VI})$ tolerant bacteria: Five milliliters of the tannery effluent collected were added to $50 \mathrm{ml} \mathrm{LB}$ broth containing chromium as Potassium dichromate $\left(\mathrm{K}_{2} \mathrm{Cr}_{2} \mathrm{O}_{7}\right)$ at different concentration (100 mg /l, $200 \mathrm{mg} / /, 300 \mathrm{mg} / /, 400 \mathrm{mg} / \mathrm{l}$ and $500 \mathrm{mg} / \mathrm{ll}$ for enrichment and selection and incubated for $48-72 \mathrm{~h}$ at 37 ${ }^{\circ} \mathrm{C}$ with shaking. A volume of $100 \mu \mathrm{l}$ from enriched culture of the samples was inoculated on Luria-Berteni (LB) agar plate with addition of $500 \mathrm{mg} / / \mathrm{Cr}^{6+}\left(\mathrm{as}_{2} \mathrm{Cr}_{2} \mathrm{O}_{7}\right.$ ) and incubated at $37^{\circ} \mathrm{C}$ for 4 days. From all samples and agar plates, a total of 42 colonies have been selected and identified. Those colonies were isolated by sub-culturing onto fresh LB plate with same concentration of added $\mathrm{Cr}^{6+}$. The isolates were purified by restreaking further on Nutrient agar (NA) and incubated for $18-24 \mathrm{~h}$ at $37^{\circ} \mathrm{C}$. Following overnight incubation in nutrient agar at $37^{\circ} \mathrm{C}$, the isolates were preserved in $30 \%$ glycerol at $-20^{\circ} \mathrm{C}$.

Cultural and biochemical tests: Cultural and biochemical tests were conducted in order to avoid the involvement of similar type of microorganism in $\mathrm{Cr}(\mathrm{VI})$ reduction studies. The shape and type of Gram reaction were microscopically studied using $18 \mathrm{~h}$ culture from agar plate. Other cultural tests performed included selective and differential media such as MacConkey (MAC) Agar, Sorbitol MacConkey (SMAC) 
Agar, Xylose Lysine Deoxycholate (XLD) Agar, Salmonella-Shigella (SS) agar, Mannitol Salt Agar(MSA), Bismuth Sulfide agar (BSA), Streptococcus Selection agar, Cetrimide agar and Eosine Methylene Blue (EMB) Agar. Biochemical tests were performed using Kliger's Iron Agar (KIA), Simmon's Citrate agar, Motility Indole Urea (MIU), Lysine Iron agar (LIA), Urea broth, Peptone water, Methyl Red-Voges Proskauer (MR-VP) broth, Nutrient Nitrate Broth (NB), carbohydrate fermentation broth with added lactose, sucrose, glucose as sole carbon source, Starch uitilization agar, Oxidase and Catalase tests. Identification of isolates obtained from pure culture was based on Gram staining, biochemical characterisitcs and growth pattern on selective and differential media according to the procedures recommended in the Bergey's Manual of Determinative Bacteriology (Holt 1984, Ewing 1986).

Estimation of total chromium content of the effluent: Tannery sample were digested and prepared for determination of total $\mathrm{Cr}$ load according to Fraga et al. (2002). The determination of $\mathrm{Cr}$ was performed on Atomic Absorption Spectrophotometer using an air- acetylene flame. The flow of gases was adjusted to obtain an oxidant flame. All measurements were made at the same wavelength and using the same hollowcathode lamp.

$\mathrm{Cr}^{6^{+}}$reduction by the strains in growth dependent manner: Nine selected isolates were studied for $\mathrm{Cr}^{6+}$ reduction in growth dependent manner. The strains were inoculated from pure cultures into broth medium with added $\mathrm{Cr}^{6+}$ to obtain resultant $\mathrm{Cr}^{6+}$ concentration of $10 \mathrm{mg} / \mathrm{l}$. Before addition of $\mathrm{Cr}^{6+}$ into inoculums, they were incubated for one hour in shake flask culture at $150 \mathrm{rpm}$ and $37^{\circ} \mathrm{C}$. Then the optical density of the inoculums is adjusted around 0.60 at $600 \mathrm{~nm}$ as a measure for equal enzyme activity. After adding $\mathrm{Cr}^{6+}$, the cultures were again incubated for $24 \mathrm{~h}$ in shake flask culture at $150 \mathrm{rpm}$ and $37^{\circ} \mathrm{C}$. After that the broth cultures were centrifuged at $5000 \mathrm{rpm}$ for 15 minutes. The supernatants were separated. The residual $\mathrm{Cr}^{6+}$ concentrations in the supernatants were measured in comparison to the initial $10 \mathrm{mg} / \mathrm{l}$.

Assay of hexavalent chromium by DPC method: DPC solution $(125 \mu \mathrm{l})$ was added to one $\mathrm{ml}$ of the supernatant collected and mixed gently. Samples then kept at room temperature for $20 \mathrm{~min}$. Then the absorbance of the color produced was measured at $540 \mathrm{~nm}$ by spectrophotometer. A standard curve was prepared to estimate the chromium concentration using different chromium concentrations ranging from 1 to $10 \mathrm{mg} / \mathrm{L}$. The absorbance was measured for each concentration by using the Di-Phenyl Carbazide (DPC) method (Bartlet and James 1996). Using the concentration versus absorbance, a standard curve was plotted. From the standard curve $\mathrm{Cr}$ concentration was determined.

\section{Results}

Isolates: Identification of isolates obtained from pure culture based on Gram staining indicated that the isolates belong to the species of Moraxella (14.3\%), Bacillus (11.43\%), Streptococcus (25.72\%), Staphylococcus (5.7\%), Salmonella (14.3\%), E. coli (14.3\%), Enterobacter (14.3\%), Hafnia alvei $(2.45 \%)$ and Alcaligenes sp. (3.5\%) respectively. The percentage of different genera isolated is shown in Fig. 1.

$\mathrm{Cr}^{6+}$ concentration and assay: It is clearly evident that the isolates selected were tolerant to $\mathrm{Cr}^{6+}$ concentration up to $500 \mathrm{mg} / \mathrm{l}$. Though the growth expression by the isolates are differential, but a general trend of growth decrease is observed with increase in $\mathrm{Cr}^{6+}$ concentration. The total chromium load of the tannery effluents analyzed was found to vary from 22 to $24 \mathrm{mg} / \mathrm{l}$ with a mean value of $23.73 \mathrm{mg} / \mathrm{l}$. Hexavalent chromium solution of different known concentration ranging from 1 to $10 \mathrm{ppm}$ was prepared and assayed by DPC method. A standard curve was prepared with these data which was used to determine the reducing ability of the selected strains. The standard curve constructed was shown in Fig 2. 


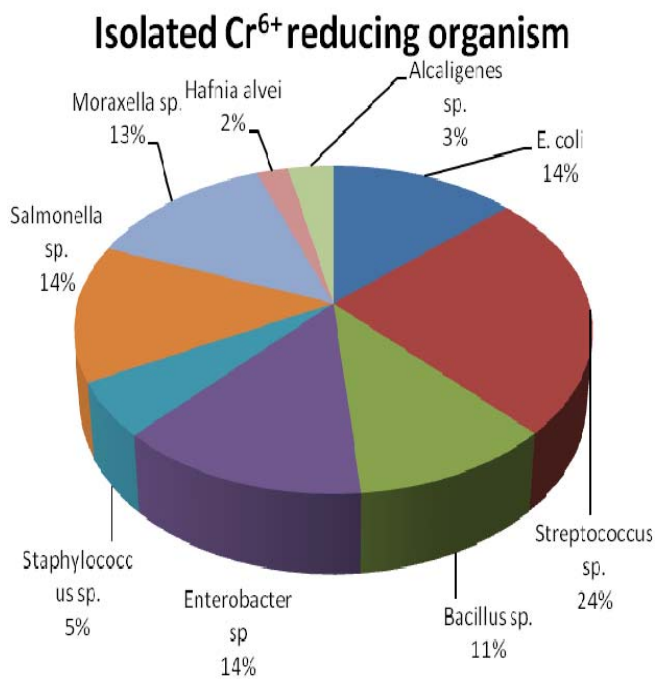

Fig. 1. Percentage of $\mathrm{Cr}^{6+}$ reducing genera isolated

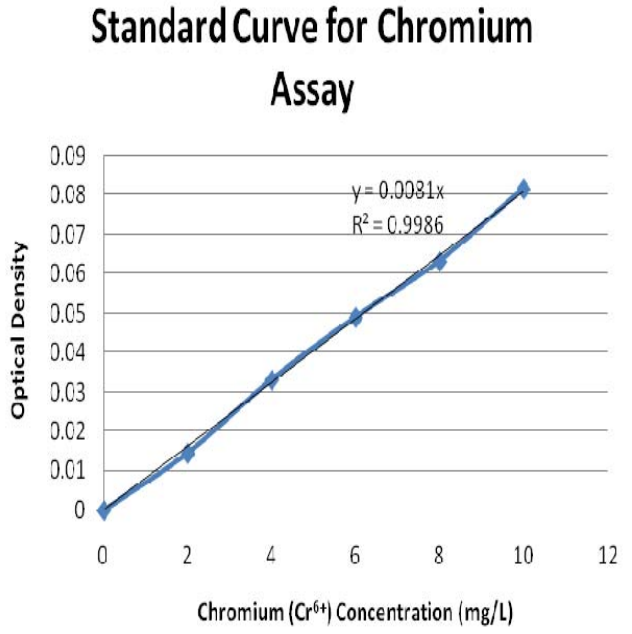

Fig. 2. Standard curve for determination of $\mathrm{Cr}^{6+}$ reduction

Table 1. Chromium reducing ability of the isolates (initial concentration $10 \mathrm{ppm}$ )

\begin{tabular}{clc}
\hline Isolate & \multicolumn{1}{c}{ Identity } & Percent reduction \\
\hline 4 & Alcaligenes sp & 20.0 \\
8 & Hafnia alvei & 22.0 \\
50 & Salmonella sp. & 17.0 \\
58 & Moraxella sp. & 38.0 \\
60 & Staphylococcus sp. & 32.0 \\
63 & Bacillus sp. & 9.0 \\
26 & Staphylococcus sp. & 16.0 \\
25 & Staphylococcus sp. & 18.9 \\
59 & E. coli & 8.0 \\
\hline
\end{tabular}

$\mathrm{Cr}^{\mathrm{r}+}$ reduction by the strains: The reducing ability varies among strains as shown in Table 1. It is clear that the selected isolates are able to reduce $\mathrm{Cr}^{6+}$ in laboratory environment. Of them Isolate 58 and 60 are most promising as they can reduce about $38 \%$ and $32 \%$ of $\mathrm{Cr}^{6+}$ added initially. They belong to the genus Moraxella and Staphylococcus respectively. Other isolates such as isolate4 (Alcaligenes sp.), 8 (Hafnia alvei), 50 (Salmonella sp.) and 25 (Staphylococcus sp.) have moderate reducing ability ranging from $18 \%$ to $22 \%$. The rest of the isolates showed poor reducing ability, less than $10 \%$. All of them can tolerate at least $500 \mathrm{mg} / \mathrm{C} \mathrm{Cr}{ }^{6+}$ in culture media. Those strains can be subjected to genetic manipulation to increase their chromium resistance capability as well as to increase their chromium reducing capability. As these organisms are indigenous of the tannery effluent, they hope to be better adapted to the environment of the effluent and will require less time for acclimation. 


\section{Discussion}

Hexavalent chromium mainly causes both acute and chronic toxicity. The chromium load found in the present investigation is very high considering the fact that the natural total chromium content of surface waters is approximately $0.5-2 \mu \mathrm{g} / \mathrm{l}$ (WHO 1996) which in turn indicates heavy chromium pollution in tannery effluents of Bangladesh. The higher toxicity and mobility of $\mathrm{Cr}^{6+}$ compared to $\mathrm{Cr}^{3+}$ makes it to be of serious concern (Ross et al. 1981). The most important toxic effects, after contact, inhalation, or ingestion of hexavalent chromium compounds include dermatitis, allergic and eczematous skin reactions, skin and mucous ulcerations, perforation of the nasal septum, allergic asthmatic reactions, bronchial carcinomas, gastroenteritis, hepatocellular deficiency, and renal oligo anuric deficiency (Baruthio 1992). In terms of carcinogenic behavior of chromium, chromate $\left(\mathrm{CrO}_{4}^{2-}\right.$ ) (which is a strong oxidizing agent) is reduced intracellularly to $\mathrm{Cr}^{5+}$ inside biological system and reacts with nucleic acids and other cell components to produce mutagenic and carcinogenic effects on biological systems (Clark 1994, McLean and Beveridge 2001).

To check chromium discharge into the environment, there are various treatment options. However, they are energy consuming and not very successful for being costly (Ohtake and Silver 1994). Besides, conventional methods for treatment of toxic chromate require a large amount of chemicals, energy and are unsuitable for small-scale leather, dye and electroplating units. In this context, biotransformation of $\mathrm{Cr}^{6+}$ into less toxic $\mathrm{Cr}^{3+}$ by certain bacteria offers a viable, economically safe and sustainable alternative (Eccles 1995). Nonetheless, development of a feasible chromate bioremediation process requires isolation of efficient chromate reducing bacterial strains, evaluation of their ability to survive, multiply and simultaneously reduce chromate in industrial waste water.

\section{Conclusion}

Reduction of very toxic $\mathrm{Cr}^{6+}$ to less toxic $\mathrm{Cr}^{3+}$ form is one of the promising approaches for combating tannery based chromium ecotoxicity in Bangladesh. Further means of bioremediation may also include biosorption and bioaccumulation of chromium by microorganisms. Development of processes coupling biological methods with chemical ones would concomitantly decrease the level of $\mathrm{Cr}^{6+}$ by reduction as well as precipitate $\mathrm{Cr}^{3+}$ through chemical reaction. This effort could make the effluents chromium free to a greater extent. As the isolates of Moraxella sp., Staphylococcus aureus, and Salmonella sp. have turned out to successfully reduce $\mathrm{Cr}^{6+}$ in this study, these can be used for the development of bioremediation process. But, for industrial adoption of remediation process, studies on feasible production of reductase enzyme or direct reduction of $\mathrm{Cr}^{6+}$ by the organisms are required for economically effective and rapid application

\section{Acknowledgements}

This work was conducted under the R \& D project entitled- 'Studies on environmental impact of tannery pollution in Bangladesh and find out biological tools for tannery waste management'. We are indebted to authorities of the Bangladesh Council of Scientific and Industrial Research (BCSIR) for funding this project and providing necessary support as needed.

\section{References}

APHA (American Public Health Association). 1998. Standard Methods for the Examination of Water and Wastewater ed. Clesceri, L.S., Greenboug, L.S. and Eaton, A.D. Washington, DC: American Public Health Association/American Water Works Association/Water Environment Federation.

Bartlett RJ, James BR. 1996. Chromium. In Methods of Soil Analysis. Part 3. Chemical Methods (Soil Science Society of America Book Series, No. 5 Methods of Soil analysis, Sparks DL (ed) Part 3, p 683-701. 
Baruthio F. 1992. Toxic effects of chromium and its compounds. Biol Trace Elem Res 32, 145-153. doi:10.1007/BF02784599

Chaudhary AJ, Goswami NC, Grimes SM. 2003. Electrolytic removal of hexavalent chromium from aqueous solutions. J Chem Tech Biotech 78, 877-883. doi:10.1002/jctb.871

Chhikara S, Dhankhar R. 2008. Biosorption of $\mathrm{Cr}(\mathrm{VI})$ ions from electroplating industrial effluent using immobilized Aspergillus niger biomass. J Environ Biol 29(5), 773-778

Clark DP. 1994. Chromate reductase activity of Enterobacter aerogenus is induced by nitrite. FEMS Microbiol. Lett 122, 233-238. doi:10.1111/j.1574-6968.1994.tb07173.x

Eccles HC. 1995. Removal of heavy metals from effluent streams-why select a biological process? Int Biodeterior Biodegrad 35, 5-16. doi:10.1016/0964-8305(95)00044-6

Ewing WH. 1986. Edwards and Ewing's identification of Enterobacteriaceae $4^{\text {th }}$ ed.. Elsevier Science Publishing Co Inc, New York, 550pp.

Faryal R, Yousaf M, Muneer K, Tahir F, Hameed A. 2007. Enhancement of $\mathrm{Cr}^{+6}$ removal by Aspergillus niger RH19 using a biofermentor. Pak J Bot 39(5), 1873 - 1881.

Fraga IC, Maria N, Oliveira MD. 2002. Determination of total chromium traces in tannery effluents by electrothermal atomic absorption spectrometry, flame atomic absorption spectrometry and UV-visible spectrophotometric methods. Talanta 58(4), 629-633. doi:10.1016/S0039-9140(02)00317-X

Gauglhofer J, Bianchi V. 1991. Chromium. In: Metals and their compounds in the environment, Merian E (ed), Wiley-VCH Publisher, New York, pp 853-878.

Holt JG. 1984. Bergey's Manual of Systematic Bacteriology. Williams and Wilkins, Baltimore.

Hooda V. 2007. Phytoremediation of toxic metals from soil and wastewater. J Environ Biol 28, 367-376.

Hossain A, Maruf MM, Monir T, Rezwan AM. Haque UI, Kazi MAI, Islam MS, Elahi SF. 2007. Heavy metal concentration in tannery solid wastes used as poultry feed and the ecotoxicological consequences. Bangladesh J Sci Ind Res 42(4), 397-416.

Kamaludeen SPB, Arunkumar KR, Avudainayagam S, Ramasamy K. 2003. Bioremediation of chromium contaminated environments. Indian J Exp Biol 41, 972-985.

McLean J, Beveridge TJ. 2001. Chromate reduction by a pseudomonad isolated from a site contaminated with chromated copper arsenate. Appl Environ Microbiol 67, 1076-1084. doi:10.1128/AEM.67.3.1076-1084.2001

Ohtake H, Silver S. 1994. Bacterial detoxification of toxic chromate. In Biological degradation and bioremediation of toxic chemicals, Choudhary GR (ed.) Dioscorides, Portland. pp. 403-415

Rafiqullah IM, Hossain AMM, llias M, Hoq MM. 2008. Chromium(VI) Reducing Native Microorganisms for Remediation of Chromium Eco-toxicity in Environment of Bangladesh. Bangladesh J Sci Ind Res 43(4), 455-466.

Raji C, Anirudhan TS. 1997. Chromium (VI) adsorption by sawdust: kinetics and equilibrium. Indian J Chem Tech $4,228-236$

Ross DS, Sjogren RE, Bartlett RJ. 1981. Behavior of chromium in soils: Toxicity to microorganisms. J Environ Qual, 10(2), 145. doi:10.2134/jeq1981.00472425001000020004x

Shakoori AR, Makhdoom M, Haq RU. 2000. Hexavalent chromium reduction by a dichromate-resistant gram-positive bacterium isolated from effluents of tanneries. Appl Microbiol Biotech 53, 348-351. doi:10.1007/s002530050033

Singh AL. 1994. Removal of chromium from waste water with the help of microbes: a review. e-JST, 1-16.

Yigit S, Ahmet A. 2006. Concentration of heavy metals in the food web of Lake Egirdir. Turk J Environ Biol 27, 475-478. 